\title{
Simplified synthesis of silver nanoparticles on graphene oxide and their applications in electrocatalysis
}

\author{
Jaroslav Filip ${ }^{1}$, Philipp Wechsler ${ }^{2}$, Josef Stastny ${ }^{1}$, Veronika Malkova ${ }^{1}$, Antonin \\ Minarik $^{3,4}$, Stepan Vinter ${ }^{1}$ and Josef Osicka ${ }^{4}$ \\ ${ }^{1}$ Department of Environmental Protection Engineering, Faculty of Technology, Tomas Bata University \\ in Zlin, Vavreckova 275, Zlín 76001, Czech Republic \\ ${ }^{2}$ Department of Chemistry and Applied Biosciences, ETH Zürich, Vladimir-Prelog-Weg 1, CH-8093 \\ Zürich, Switzerland \\ ${ }^{3}$ Department of Physics and Materials Engineering, Faculty of Technology, Tomas Bata University in \\ Zlin, Vavreckova 275, 76001 Zlin, Czech Republic \\ ${ }^{4}$ Centre of Polymer Systems, Tomas Bata University in Zlín, Tř́ida Tomáše Bati 5678, 76001 Zlín, \\ Czech Republic \\ E-mail Jaroslav Filip: jfilip@utb.cz
}

Received xxxxxx

Accepted for publication $\mathrm{xxxxxx}$

Published xxxxxx

\begin{abstract}
In this work the possibility was investigated to synthesize in-situ silver nanoparticles (AgNP) on graphene oxide (GO) surface without commonly used additional reducing or alkalizing agents or increased temperature. Using diverse microscopic (AFM, TEM) and spectroscopic methods, it was proved that very small AgNPs were formed on GO by simple incubation for 2 hours a mixture of $\mathrm{GO}$ dispersion and $\mathrm{AgNO}_{3}$. The prepared nanomaterial ( $\mathrm{GO} \_\mathrm{Ag}$ ) was also assessed using electrochemical methods and it exhibited electrochemical behavior similar to GO_Ag nanomaterial prepared with a help of citric acid as a reducing agent. Furthermore, it was found that i) electrochemical reduction of the GO_Ag on electrode surface decreased the voltammetric response even though this step has increased the surface conductivity and ii) GO_Ag can be employed for sensing of chlorides with detection limit of $79 \mu \mathrm{M}$ and a linear range up to $10 \mathrm{mM}$. It could also provide electrochemical response toward chloroacetanilide herbicide metazachlor. Hence, the reducing capabilities of GO were proved to be applicable for insitu synthesis of metal nanoparticles with the highest possible simplification and the as-prepared nanomaterials could be employed for fabrication of different electrochemical sensors.
\end{abstract}

Keywords: graphene oxide, silver, nanoparticles, chloride, voltammetric sensors

\section{Introduction}

Metal and metal oxide nanoparticles has been recently recognized as potent and versatile catalysts and electrocatalysts due to their unique physical, electrochemical and optical properties [1-3]. Therefore methods for their reproducible, fast and cheap synthesis have been sought. Most metal nanoparticles are synthesized via bottom-up method relying on reduction of $\mathrm{Me}^{\mathrm{n}+}$ ions in solution to $\mathrm{Me}^{0}$ atoms which assembly into nanoparticles. Their shape and size are determined by different parameters of the synthesis, i.e. $\mathrm{pH}$, temperature, reaction time, reactant concentrations and so on. The same implies also for silver nanoparticles (AgNPs) which can be prepared by reduction of $\mathrm{AgNO}_{3}$ by hydrazine hydrate [4], sodium borohydrate [5, 6] - both strong but rather hazardous reducing agents, by plants-derived compounds [7] or other "bio-inspired" reducing agents including saccharides 
[8] or living bacteria cells [9]. Also photochemical or electrochemical approaches have been reported [10, 11]. Apart from these, a "classical" Turkevich method is employed very often employing sodium citrate for reduction of gold [12, 13] and silver [14] ions because of its feasibility and environmental suitability (basically no toxic waste are produced).

Besides liquid phase synthesis, AgNP and other metal nanoparticles can be also synthesized on some solid substrate including graphene and its derivatives, e.g. graphene oxide (GO). GO is a nanomaterial comprising of one-atom thin two dimensional crystals of highly ordered carbon with structure disturbed by carboxyl, hydroxyl, epoxy and similar oxygen moieties resulting from the oxidation process [15]. It makes GO particles easy-to-handle, flexible, hydrophilic and introduces partial negative electrical charge which is known to be behind a good affinity of $\mathrm{Me}^{\mathrm{n}+}$ ions towards GO. The latter effect leads to larger number of the synthesized nanoparticles attached to the GO surface. It has been confirmed that the Turkevich method can be also used for synthesis of AgNPs attached to the GO surface [16, 17].

In 2002 Choi et al. reported spontaneous reduction of $\mathrm{AuCl}_{4}{ }^{-}$on sidewalls of single-wall carbon nanotubes [18]. This work gained some attention and later GO was employed in similar synthesis of Pd, Au or Ag nanoparticles [19-21]. The spontaneous reaction is believed to be driven by difference in redox potentials of GO (which is $+0.48 \mathrm{~V} v s$. SCE) and redox potential of metallic ions. This principle was proven to be applicable for synthesis of $\mathrm{Rh}, \mathrm{Pd}, \mathrm{Cu}$ and $\mathrm{Au}$ nanoparticles $[22,23]$ and also for a synthesis of AgNPs [20]. However, the described methods relied mostly on increased temperature and/or alkali environment ( $\mathrm{NaOH}$ addition), as reported by many authors [21, 24-31]. It is believed that under alkaline conditions GO's edge hydroxyls can be "activated" (ionized to semiquinone) which is how GO can be turned to a reducing agent (see, for example, [32-34]). But, obviously, such "activation" is not necessarily needed for running of the described redox reaction [27] with the conjugation system in graphene oxide being the proposed "alternative" electron donor [20].

It is also agreed that GO's carboxyls are ionized under neutral conditions [35] and offer increased number of bonding sites for metal cations, including $\mathrm{Ag}^{+}$[34]. Other authors suggested that hydroxyl groups may play more important role in the nucleation [20].

AgNPs synthesized on surface of graphene-derived nanoparticles exhibited electrocatalytic properties. For example Kaur et al., 2013, reported enhanced electrocatalysis of ascorbic acid, tryptophan and other small molecules using electrode modified by the reduced graphene oxide with synthesized $\mathrm{Ag}$ nanoparticles (reduction of both $\mathrm{GO}$ and $\mathrm{Ag}^{+}$ was triggered by addition of $\mathrm{NaOH}$ ) [28]. Furthermore, electrodes made of silver or modified by silver nanoparticles or nanowires can be also used for halide ion sensing because of known capability of $\mathrm{Ag}$ to spontaneously form complexes with $\mathrm{Cl}^{-}, \mathrm{I}^{-}, \mathrm{Br}^{-}$and $\mathrm{F}^{-}$. These complexes can be electochemically oxidized, providing voltammetric (cyclic voltrammetry, differential pulse voltammetry...) analytical signal [36-46].

In our work the fabrication of $\mathrm{GO} \_\mathrm{Ag}$ nanohybrid has been further simplified, that is, the reduction of $\mathrm{Ag}^{+}$was performed at room temperature and without any additional agents, only with GO. Under these conditions silver was incorporated onto GO nanosheet surface, forming GO_Ag nanohybrid with a clear voltammetric response ascribed to oxidation of $\mathrm{Ag}$ and reduction of the formed silver oxide. After characterizations, the prepared GO_Ag nanohybrid has been employed for voltammetric detection of chloride with an observed linear response between 0.25 and $10 \mathrm{mM}^{-} \mathrm{Cl}^{-}$in phosphate buffer and it was also employed for detection of $\mathrm{FeCl}_{3}$ (commonly used coagulation agent in water treatment processes) in tap water and the voltammetric response toward a chloroacetanilide pesticide was also successfully recorded. Interestingly, a good performance in $\mathrm{Cl}^{-}$detection was achieved when GO_Ag has been kept non-reduced, the voltammetric response was recorded despite the low conductivity of GO. The obtained results can be further employed in development of reliable, high-performance, robust and stable detection devices for possible industrial or commercial use. To the best of our knowledge such achievement has been reported for the first time.

\section{Materials and methods}

\section{$2.1 \quad$ Reagents}

Graphene oxide (GO; aqueous dispersion $4 \mathrm{mg} \mathrm{mL} \mathrm{mL}^{-1}$, Graphene Laboratories Inc., USA); all other chemicals were of analytical grade, supplied by Lachema, Czech republic, or Penta Chemicals, Czech republic.

\subsection{GO_Ag preparation and modification of electrodes}

Typical GO_Ag samples have been prepared by simple addition of $2.4 \mathrm{~mL}$ of $\mathrm{GO}\left(4 \mathrm{mg} \cdot \mathrm{mL}^{-1}\right)$ into $90 \mathrm{~mL}$ of deionized water (DW) followed by a drop-wise addition of $1.2 \mathrm{~mL}$ of $100 \mathrm{mM} \mathrm{AgNO} 3$ (aqueous solution). To some samples also 1.2 $\mathrm{mL}$ of $100 \mathrm{mM}$ citric acid as the reducing agent was added, in such cases the synthesised nanohybrid is denoted to as GO_Ag_C. The mixture was stirred at room temperature, in dark, using magnetic stirrer for $2 \mathrm{~h}$, unless stated otherwise. After the incubation, the mixture was centrifuged (30 min, 11500 RPM), supernatant was discarded, the precipitate was resuspended in DW and the centrifugation was repeated. Total number of centrifugation steps was 3 . The precipitate after the last centrifugation was dried in the oven at $60^{\circ} \mathrm{C}$. From the obtained powder an aqueous dispersions containing $1 \mathrm{mg} . \mathrm{mL}^{-}$ 
${ }^{1} \mathrm{GO} \_$Ag were prepared using 30 min ultrasonic dispergation. $10 \mu \mathrm{L}$ (unless stated otherwise) of dispersions was drop-casted on surface of pre-cleaned (mechanical polishing using alumina paste and ultrasonic cleaning in DW) glassy carbon electrodes (GCE; geometric surface area of $0.07 \mathrm{~cm}^{2}$; BASi, USA). After drying out (room temperature, free atmosphere), the GO_Ag formed a stable film on GCE surface which could be observed by naked eye.

\subsection{Material characterization}

UV-VIS characterization was performed by a spectrophotometer UNICAM UV500 (Thermo Scientific). Diluted aqueous dispersions of GO_Ag were measured in quartz cuvettes using wavelength range of 200 to $600 \mathrm{~nm}$. Xray diffracion (XRD) spectra were obtained by X'PertPRO (Malvern PANanalytical, Netherland) device with $\mathrm{Cu} \mathrm{K} 1 \alpha$ primary X-ray source of $\lambda=0.15406 \mathrm{~nm}$. Samples were prepared by pipetting GO_Ag dispersions on microscopic glass and consequent drying under the same conditions as in the case of GCE modifications. The same way of sample preparation was used also for atomic force microscopy (AFM) characterization, which was performed using Bruker Dimension ICON (Bruker Corporation; US) equipped with a ScanAsyst-Air probe with a resonant frequency of $70 \mathrm{kHz}$ and a stiffness constant of $0.4 \mathrm{~N} \mathrm{~m}^{-1}$ (Bruker Corporation; US). For measurements PeakForce Tapping method was chosen. Transmission electron microscopy (TEM and high resolution TEM - HR-TEM) images were obtained by JEOL JEM 2100 device equipped with a LaB6 cathode and using the acceleration voltage of $200 \mathrm{kV}$. Infrared (FTIR) spectra were collected using Nicolet iS10 (Thermo Scientific, USA). The sample preparation for FTIR is described in the appropriate section. X-ray fluorescence (XRF) measurement were performed on spectrometer ElvaX (Elvatech, Ukraine) by placing as-prepared material without any treatment into the equipment's sample holder. Atomic absorption spectrometry was performed using ContrAA 800 D device (Analytik Jena AG, Germany) after leaching silver from the known amount of the prepared material into $25 \mathrm{~mL}$ of $5 \% \mathrm{HNO}_{3}$. For collection of X-ray photoelectron spectra (XPS) a Thermo Scientific K-Alpha compact XPS system (Thermo Fisher Scientific, UK) equipped with a micro-focused, monochromatic Al K $\alpha$ X-ray source (1486.68 eV) was used. Pass energy of $50 \mathrm{eV}$ was used for the narrow regions measurements and surface etching was achieved with Ar flood gun for $10 \mathrm{~s}$.

\subsection{Electrochemical characterization}

All measurements were made in glass measuring vessel filled with an electrolyte (indicated in the figure captions) and using three-electrode connection with a Pt plate (Metrohm, Switzerland) and modified GCEs electrodes as counter and working electrodes, respectively. $\mathrm{Ag} / \mathrm{AgCl} / 3 \mathrm{M} \mathrm{KCl}$ electrode
(Metrohm, Switzerland) was used as the reference electrode. It should be noted that there can probably be some leakage of $\mathrm{Cl}^{-}$ions from the electrode which may bias the measurement, but the electrode junction was well-sealing and no bias were observed. PGSTAT101 (Metrohm, Netherland) and ZIVE SP1 (WonATech, Korea) potentiostat/galvanostats were used for voltammetric and EIS measurements, respectively.

To prepare electrodes denoted to as GCE|ErGO_Ag or GCE|ErGO_Ag_C, previously prepared electrodes GCE $\mid$ GO_Ag or GCE $\mid$ GO_Ag_C have been treated chronoamperometrically in the above-described electrochemical cell under the following conditions: electrolyte $100 \mathrm{mM}$ phosphate buffer, $\mathrm{pH} 7$ (PB), potential $1.4 \mathrm{~V}$, reduction time $15 \mathrm{~min}$. No aeration, deaeration or stirring of the electrolyte was performed.

\section{Results and discussion}

\subsection{Spectroscopic and microscopic characterization}

UV-VIS spectrophotometry of aqueous dispersions of the GO_Ag revealed absorption peaks at $230 \mathrm{~nm}$ and at about 308 $\mathrm{nm}$ (figure $1 \mathrm{~A}$ ), which is typical for graphene oxide [28, 47], namely for $\pi \rightarrow \pi *$ transitions of $\mathrm{C}=\mathrm{C}$ bonds in graphenic rings and $\mathrm{C}=\mathrm{O}$ bonds, respectively [48]. The above-mentioned and many other studies have also reported an emergence of an absorbance band at about $400 \mathrm{~nm}$ in presence of $\mathrm{AgNP}$ [47, 49], however, these peaks were not observed in our case. It was reported for example by Pasricha et al. that silver nanoparticles with "activated surface plasmons" could be synthesized only under alkaline conditions [32] which is not a case of the current work. Certainly, $\mathrm{pH}$ is what matters here since the typical surface plasmon resonance peak emerge at higher $\mathrm{pH}$ [34]. Indeed, it was reported that silver clusters/nanoparticles synthesized on GO surface do not necessarily exhibit the distinguishable absorbance peak, instead AgNP is displayed as the higher "background" of the absorbance spectrum [50]. Lower diameter of spherical nanoparticles also decreases the absorption cross-section [51] and, last but not least, net amount of AgNPs in the bulk GO_Ag nanomaterial is quite low. Another result of the UVVIS characterization is that both GO_Ag and GO_Ag_C spectra retained their "GO-like" features, suggesting that any change in $\mathrm{GO}$ composition induced by reaction with $\mathrm{Ag}^{+}$has 

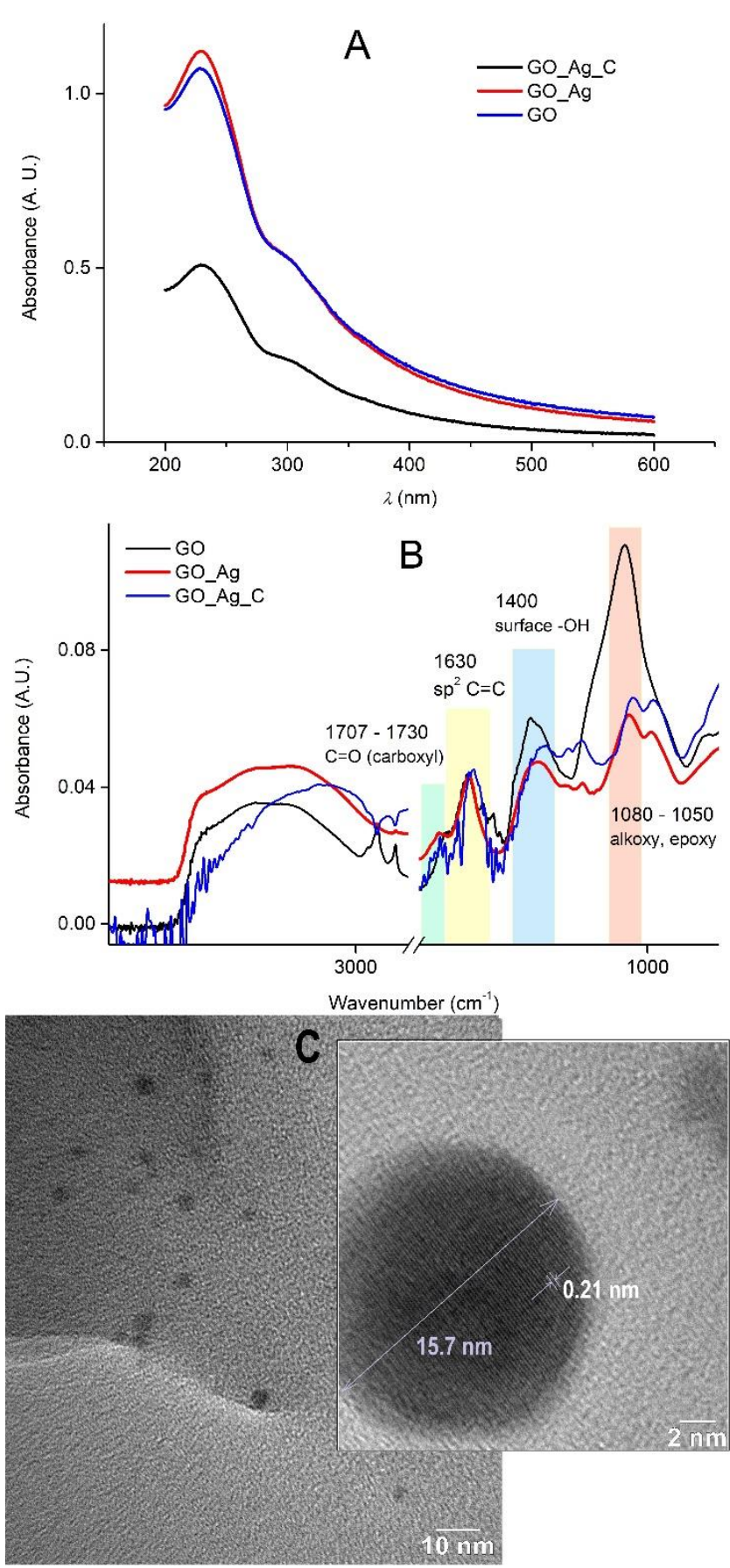

Figure 1: A) UV-VIS spectra of GO_Ag_C (black), GO_Ag (red) and GO (blue); B) FTIR spectra of GO (black) and GO_Ag (red) and GO_Ag_C (blue) normalized to the intensity at $1632 \mathrm{~cm}^{-1}$ and with the highlighted relevant absorption bands; C) TEM and HRTEM (inset) images of GO_Ag nanoparticles, two places of the same sample. Scale bars are indicated in the images.

not involved $\mathrm{C}=\mathrm{O}$ and $\mathrm{C}=\mathrm{C}$ bonds. More details, however, were offered by FTIR results.

FTIR measurements were performed on the GO, GO_Ag and GO_Ag_C dispersions drop-casted on $\mathrm{Al}$ foil and dried under normal atmospheric pressure, room temperature. From spectra in figure $1 \mathrm{~B}$ it can be seen that both GO and GO_Ag

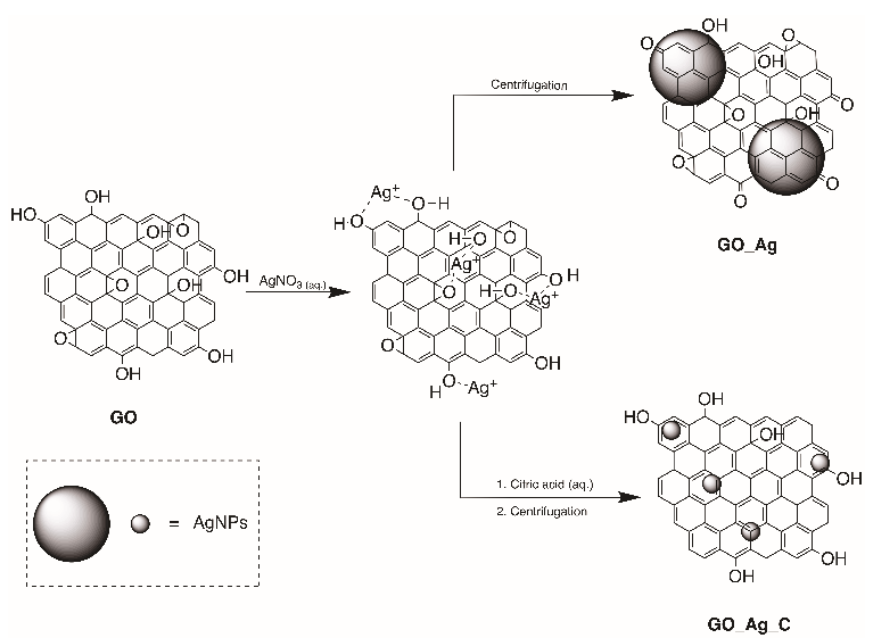

Scheme 1: The proposed mechanism of synthesis of silver nanoparticles in absence (GO_Ag) and presence (GO_Ag_C) of citric acid.

prepared without the reducing agent exhibited a broad absorption band between 3000 and $3700 \mathrm{~cm}^{-1}$ assigned to adsorbed water and a peak at $1632 \mathrm{~cm}^{-1}$ assigned to nonoxidized, $\mathrm{sp}^{2}$ hybridized $\mathrm{C}=\mathrm{C}[20,52]$. Their unchanged position in the GO_Ag sample suggests that these parts did not undergo any change/reaction during incorporation of silver. On the other hand, other bands were significantly shifted which points to electrostatic interaction of GO's active groups with $\mathrm{Ag}^{+}$. Namely, band assigned to $\mathrm{C}-\mathrm{O}$ bond in alkoxy/epoxy groups $[48,52,53]$ was shifted from 1083 to $1070 \mathrm{~cm}^{-1}$ in case of GO_Ag and further to $1050 \mathrm{~cm}^{-1}$ at GO_Ag_C. Small peak assigned to $\mathrm{C}=\mathrm{O}$ in carboxyls $[47,54$, 55] shifted from 1707 to $1730 \mathrm{~cm}^{-1}$ as well as a peak at about $1400 \mathrm{~cm}^{-1}$ assigned to hydroxyl moieties of GO structure [52] also shifted towards lower wavenumber values after incubation with Ag. This shift was even larger in case of GO_Ag_C. These results suggest that $\mathrm{Ag}^{+}$ions may be electrostatically anchored to oxygen moieties of GO nanosheets. To achieve more information, the obtained spectra should be normalized to the absorption band which is supposed to be attributed to a bond contained in all samples. For this purpose $1632 \mathrm{~cm}^{-1}$ band corresponding to $\mathrm{C}=\mathrm{C}$ bonds $[20,48,52]$ was chosen and, after the normalization, substantial decrease in alkoxy region was observed together with a decrease in a hydroxyl absorbance band around 1400 $\mathrm{cm}^{-1}$ and a slight increase could be observed at $1730 \mathrm{~cm}^{-1}$. Similar trend was observed also for GO_Ag_C sample, although the decrease of both surface hydroxyls and alkoxy/epoxy moieties was smaller than in the absence of citric acid. It would be reasonable to assume that $\mathrm{Ag}^{+}$is captured by hydroxyl/carboxyl moieties, which is in agreement with the mechanism proposed before [20, 32, 54]. In addition, the observed diminish of alkoxy/epoxy groups is a result of $\mathrm{Ag}^{+}$-induced hydrolysis to hydroxyls. It is probable that these newly formed groups have also capability to bond 
$\mathrm{Ag}^{+}$, which is why they do not display themselves as the increase in the respective absorption band. This bond may also involve electron transfer, that is, alkoxy/epoxy may serve as electron donating moietis, as suggested by Wang et al. [56].

$\mathrm{XRD}$ is a method for determination a structural properties of ordered materials, including silver nanoparticles where a peak at Bragg angle $2 \theta=40^{\circ}$ has been reported by many authors indicating $\mathrm{Ag}$ atoms packed regularly in the formed nanoparticles [28, 40]. Interestingly, no such peak has been observed at GO_Ag and GO_Ag_C (figure S1 A). Possible explanation is that $\mathrm{Ag}$ atoms are arranged in smaller clusters which are below determination level of the used XRD tool, which is also supported by a recent study [48]. XRD peaks at $2 \theta$ of 10.47 and $11.33^{\circ}$ have been observed for GO_Ag and GO_Ag_C, respectively. They can be attributed to ordered arrangement of GO material [28, 40, 52, 57]. From Bragg equation $\lambda=2 d \sin \theta$ (wavelength $\lambda$ for the given instrument setup is $0.15406 \mathrm{~nm}$ and $\sin \theta$ can be calculated from the position of the given XRD peak), lattice size $d$, or the distance between two adjacent basic units that form the regular structure, can be calculated. Obtained values of $d=0.84$ and $0.78 \mathrm{~nm}$ for GO_Ag and GO_Ag_C, respectively, suggested that without the reducing agent slightly larger space is kept between individual GO_Ag layers than between GO_Ag_C, which may be attributed to at least some mild reduction caused by citric acid. Other XRD investigations of GO reduction [28, 40] have confirmed results achieved here, because it has been reported that after the efficient GO reduction the distance between individual sheets decreases to approximately $0.3-$ $0.4 \mathrm{~nm}[53,58,59]$. XRD spectra also allowed for calculation of an average domain size using Scherrer formula $s=K$ $\lambda / \beta \cos \theta$ where $s, K$ and $\beta$ stands for a mean domain size, a shape factor (0.9) and a broadness of the peak in half its maximum intensity (FWHM) in radians, respectively. For 2D materials the calculated $s$ values can be used for estimation of numbers of adjacent layers stacked together if the diffraction peak originates from the waves reflected from the plane parallel to the stacked sheets and if the $d$ spacing between the sheets is known. Sizes of 89.7 and $47.1 \mathrm{~nm}$ were calculated for GO_Ag and GO_Ag_C, which corresponds to approximately 107 and 60 layers, respectively. This is much more than values reported elsewhere $[53,58,59]$, but it must be taken into account that the GO_Ag and GO_Ag_C samples were in a form of a solid film. This arrangement obviously strongly enhanced the stacking of individual nanolayers.

To confirm the presence of silver in the prepared nanohybrid, XRF analysis of the synthesized material in the form of powder was performed. Measurements revealed XRF peak attributed to silver in GO_Ag, while no sign of it was observed in spectrum of GO measured for comparison. The spectra can be seen in figure S1 B. Because this method could not return the bulk silver concentration, another approach was used where GO, GO_Ag and GO_Ag_C were leached in 25 $\mathrm{ml}$ of $5 \% \mathrm{HNO}_{3}$ for $30 \mathrm{~min}$. Then mixtures were filtered and obtained liquid phases were fed to flame atomic absorption spectrometer (AAS). The results revealed that GO_Ag contained $0.196 \pm 0.002 \%(\mathrm{w} / \mathrm{w})$ of $\mathrm{Ag}$. Similar value $(0.239 \pm 0.004 \%)$ was revealed for $\mathrm{GO} \mathrm{Ag} \mathrm{C}$ while GO without silver, measured for comparison, revealed negligible Ag amount (0.01\%).

The redox state of silver in GO_Ag and GO_Ag_C was determined by XPS. For both samples a peak doublet at binding energy of $368.2 \mathrm{eV}$ and $374.3 \mathrm{eV}$ were observed (figure S1 C), typical for zero-valent silver [60]. On the other side, the main peak exhibited full width at half maximum (FWHM) parameter of 1.22 (GO_Ag) and 1.28 (GO_Ag_C) which is more than 1.12 reported for $\operatorname{Ag}(0)$ and is closer to 1.22 reported for $A g(I)$ [60]. It may be concluded that silver in both GO_Ag and GO_Ag_C is partially oxidized, supposingly as a result of exposition of the synthesized nanomaterials to air. Further evaluation of $\mathrm{C} 1$ s peaks (figure S1 D) revealed significant portion of $\mathrm{sp}^{3}$-hybridized $\mathrm{C}$ (typical for graphene oxide) as well as $\mathrm{sp}^{2}$ carbon hybridization typical for reduced forms of GO. The latter form became prevalent after the surface etching which is a result of the GO reduction caused by ion bombardment [61] during the procedure. That the GO_Ag and GO_Ag_C have retained the oxidized form of graphene is obvious also from the oxygen content, that is, 30.1 and $30.8 \%$ for the GO_Ag and GO_Ag_C, respectively, which is dropped to approximately $10 \%$ after the etching. From survey scans also Ag concentration was determined for GO_Ag and GO_Ag_C to be 1.22 and 0.57 atomic percent, respectively. These values are higher than the ones observed by AAS after the acidic leaching obviously because XPS provides information about the surface composition instead of the bulk one. It can be concluded that some GO sheets are certainly stuck together without AgNPs grown between them.

TEM revealed presence of high density nanoparticles on the GO surface (see figure $1 \mathrm{C}$ and figure S2). For GO_Ag mostly small regular nanospheres with approximated diameter of about $5 \mathrm{~nm}$ were observed, but also larger particles (figure $1 \mathrm{C}$ inset), up to approximately $20 \mathrm{~nm}$. It also revealed fringes with spacing of $0.21 \mathrm{~nm}$. This is close to a value reported for $\operatorname{Ag}(200)$ crystaline lattice [40]. It should be noted most of the HR-TEM spotted nanoparticles shown regular fringes pointing to high monocrystalinity. The larger clusters were not so obvious at GO_Ag_C samples (figure S2). It is reasonable to speculate that the observed difference in nanoparticle size is responsible for observed divergences in electrochemical properties (discussed later), mainly because of different active surface area of silver nanoparticles. Furthermore, it can be seen that number of nanoparticles is not very high, in comparison with other reports [9, 32]. Another fact inferred from the measurement is that the graphene oxide treated without any additional agents has been defragmented into some smaller debris (see figure S2). 
Atomic force microscopy (AFM) analysis also revealed presence of small nanoparticles on GO surface, both with and without the employment of reducing agent. Profiling the obtained images have revealed the height of the observed patterns to be approximately between 1 and $2.5 \mathrm{~nm}$ (see inset profiles in figure S3). To obtain more details, grain analysis software tool was employed, as described in the Supplementary Information file. By such analysis mean grain size for GO_Ag_C was found to be $3 \mathrm{~nm}$ whereas for GO_Ag it was $5.8 \mathrm{~nm}$. Frequency count analysis of grain size distribution have found that there are two main peaks in the size distribution curve for GO_Ag_C while curves for $\mathrm{GO} \_\mathrm{Ag}$ tend to be less broad, but their peaks differ between particular samples (figure S4). These results accomplish the ones obtained by TEM where features of size of approximately unites of nanometers are spotted as well as object up to 10-20 $\mathrm{nm}$ in diameter. These results are in agreement with other experiments where authors claimed that reaction of $\mathrm{Ag}^{+}$with GO containing numerous oxygen moieties leads to formation of higher amount of smaller nanoparticles instead of smaller amount of larger ones [20].

All the results described above suggest the mechanism of silver nanoparticle synthesis which is illustrated in the scheme 1 .

\subsection{Electrochemical response of GCE/GO_Ag}

In first experiment series GCE electrodes modified by GO_Ag nanomaterials were tested using cyclic voltammetry (CV) with a $100 \mathrm{mM}$ phosphate buffer $\mathrm{pH}=7(\mathrm{~PB})$ as a supporting electrolyte. From figure 2 it is obvious that electrochemically active silver is present in the material modifying the electrode surface while a GO treated without $\mathrm{AgNO}_{3}$ provides no electrochemical signal under the given conditions. In accordance with other studies it can be expected that anodic voltammetric peak can be attributed to oxidation of silver $\left(\mathrm{Ag} \rightarrow \mathrm{e}^{-}+\mathrm{Ag}_{\mathrm{X}} \mathrm{O}_{\mathrm{Y}}\right)$ while the cathodic waves represents reduction of the formed silver oxides [41, 42]. These measurements also revealed few other facts: i) the silver moiety can be oxidized and reduced both in the presence and absence of chloride ions, but the presence of $\mathrm{Cl}^{-}(4.75 \mathrm{mM})$ shifted the oxidation peak to significantly lower values (by $186 \pm 6 \mathrm{mV})$. This is because formation of $\mathrm{AgCl}$ complex which is oxidized at lower potential - see discussion in subsequent sections; ii) both oxidation and reduction peaks decreased after several CV scans; iii) shapes of the peaks at first few scans suggested a presence of different redox states of silver in GO_Ag. It is reasonable to expect a difference between first $\mathrm{CV}$ scan and the consecutive ones since the modified electrodes are exposed to oxygen in free air which may oxidize a portion of the Ag nanoparticles.

The above results as well as their comparison with measurements performed with GCE $\mid \mathrm{GO} \_$Ag_C electrodes (data not shown) indicated that the GO_Ag nanohybrid prepared without any reducing agent exhibited similar electrochemical features as graphene-Ag nanocomposite prepared with citric acid as a reduction agent described in the literature [40]. Similar decrease in both oxidation and reduction peak was observed also by Bhat et al., 2015 [30] and, interestingly, Chiu et al. (2009) [43] investigated a detection of halide by a silver electrode, however they claimed no redox peak were observed without a $\mathrm{Cl}^{-}$addition. On the other side Zhang et al. (2016) [62] reported electrochemical oxidation of silver nanoparticles producing a distinctive oxidation peak, which was decreased after addition of $\mathrm{Cl}^{-}$. Such behavior is explained in the term of competitiveness between oxidation of $\mathrm{Ag}$ and oxidation of $\mathrm{AgCl}$ complex which is easily formed in presence of chloride in the solution and typically applied in electrochemical halide detection [36, 40, 43]. The achieved results are also in accordance with studies where occurrence of both peaks (i.e. oxidation of silver to silver oxide and formation of $\mathrm{AgCl}$ complex) on one voltammetric scan has been observed [41, 42]

\subsubsection{Preparation conditions and electrochemical reduction}

In other sereies of electrochemical measurements an initial concentration of reactants was investigated using $\mathrm{CV}$. In figure $3 \mathrm{~A}$ voltammograms are shown for GCE electrodes modified with GO_Ag_C nanoparticles prepared with different initial concentration of $\mathrm{AgNO}_{3}$. Obvious increase of peaks ascribed to reversible oxidation and reduction of silver in absence of chloride was observed with increased $\mathrm{AgNO}_{3}$ concentration. This is an expected result of possible deposition of higher amount of silver on GO surface.

To assess the incubation time influence four batches of the GO_Ag nanomaterial were prepared using $10 \mathrm{~min}, 1,2$ and 7 $\mathrm{h}$ of stirring $\mathrm{GO}$ and $\mathrm{AgNO}_{3}$ containing solution. Figure $3 \mathrm{~B}$ reveals that silver oxide peak heights increased with the incubation time up to $2 \mathrm{~h}$, where they reached their maximum and $7 \mathrm{~h}$ incubation has not provided any better results. In all cases substantial drop in peak potential was observed after $\mathrm{Cl}^{-}$ addition suggesting that $\mathrm{AgCl}$ was successfully formed in all cases. It can be assumed that, under the given conditions (especially temperature and $\mathrm{AgNO}_{3}$ concentration), integration of the two components, that is, $\mathrm{GO}$ and $\mathrm{Ag}^{+}$, proceeds successfully, but the longer incubation leads to some form of degradation of the formed structure or unwanted aggregation of the nanoparticles. Therefore 2 hours were chosen as an acceptable time of preparation.

As another step in the electrochemical characterization, voltammetric (SWV) response to chlorides was measured using GCE $\mid \mathrm{GO} \_$Ag and GCE $\mid \mathrm{GO} \_$Ag_C electrodes as well as the ones that were electrochemically reduced before the measurement (GCE|ErGO_Ag and GCE|ErGO_Ag_C). Measurements (Square wave voltammetry, SWV) were typically performed in PB before and after an addition of 5 $\mathrm{mM} \mathrm{KCl}$. Here it is important to note that the upper limit of the voltage range applied during SWV scans was set to be 
below the voltage at which Ag oxidation was observed. Hence the direct Ag oxidation is avoided which may have positive effect on stability and reproducibility of the observed voltammetric signal.
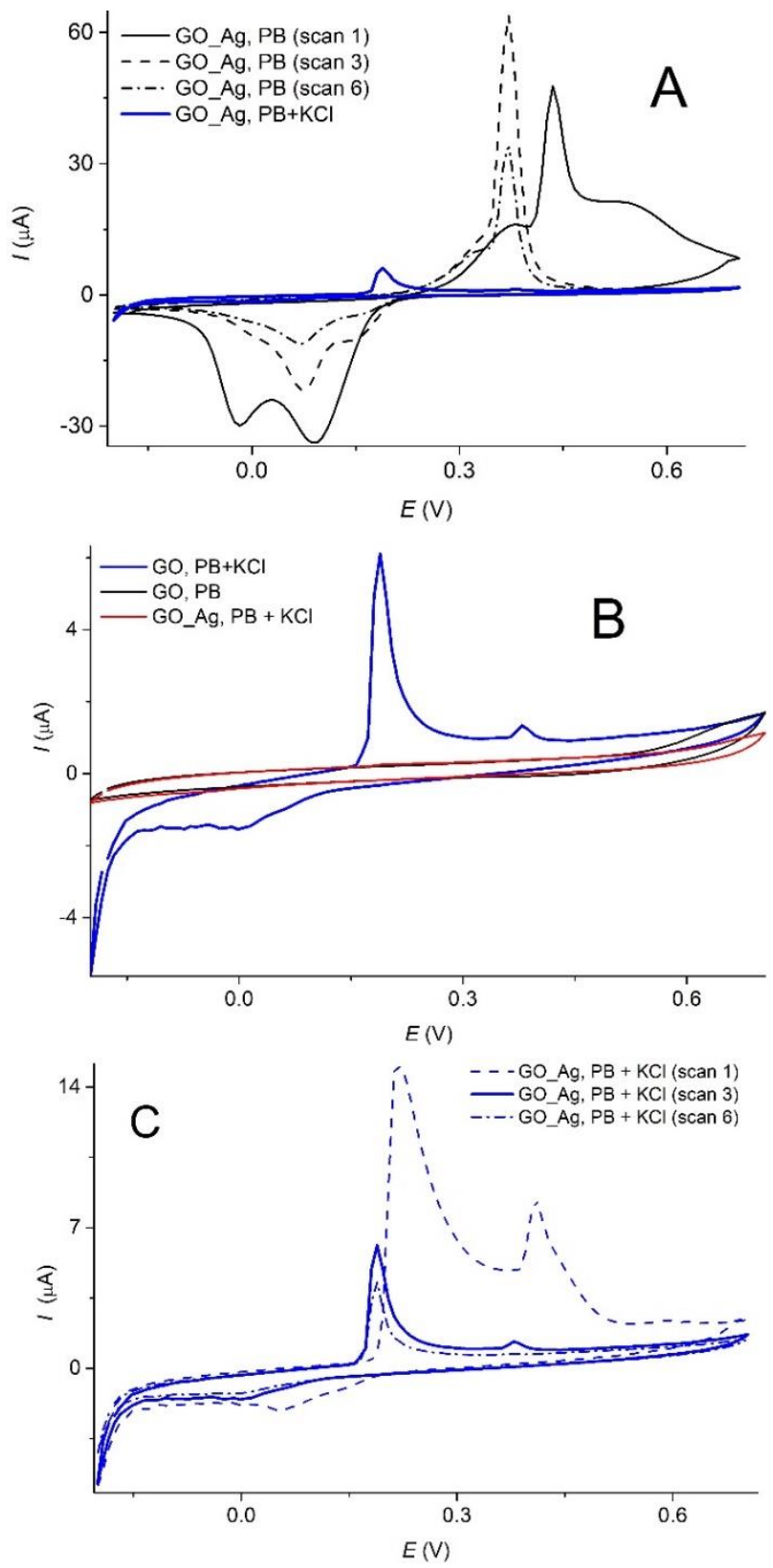

Figure 2: A) CV of GCE/GO_Ag in PB, $1^{\text {st }}$ (black solid), 3 $3^{\text {rd }}$ (black dashed) and $6^{\text {th }}$ (black dot-dashed) scan compared to the same electrode measured after addition of $4.75 \mathrm{mM} \mathrm{KCl}$ (blue solid). B) GCE/GO_Ag electrode measured in PB containing $4.75 \mathrm{mM} \mathrm{KCl}\left(3^{\text {rd }}\right.$ scan - blue solid) compared to response of GCE/GO measured in $P B$ (black) containing $4.75 \mathrm{mM} \mathrm{KCl}$ (red). C) GCE/GO_Ag electrode measured in $P B$ containing $4.75 \mathrm{mM} \mathrm{KCl}\left(1^{\text {st }}\right.$ scan - dashed; $3^{\text {rd }}$ scan solid; $6^{\text {th }}$ scan - dotted). Scan rate was $100 \mathrm{mV} \cdot \mathrm{s}^{-1}$.
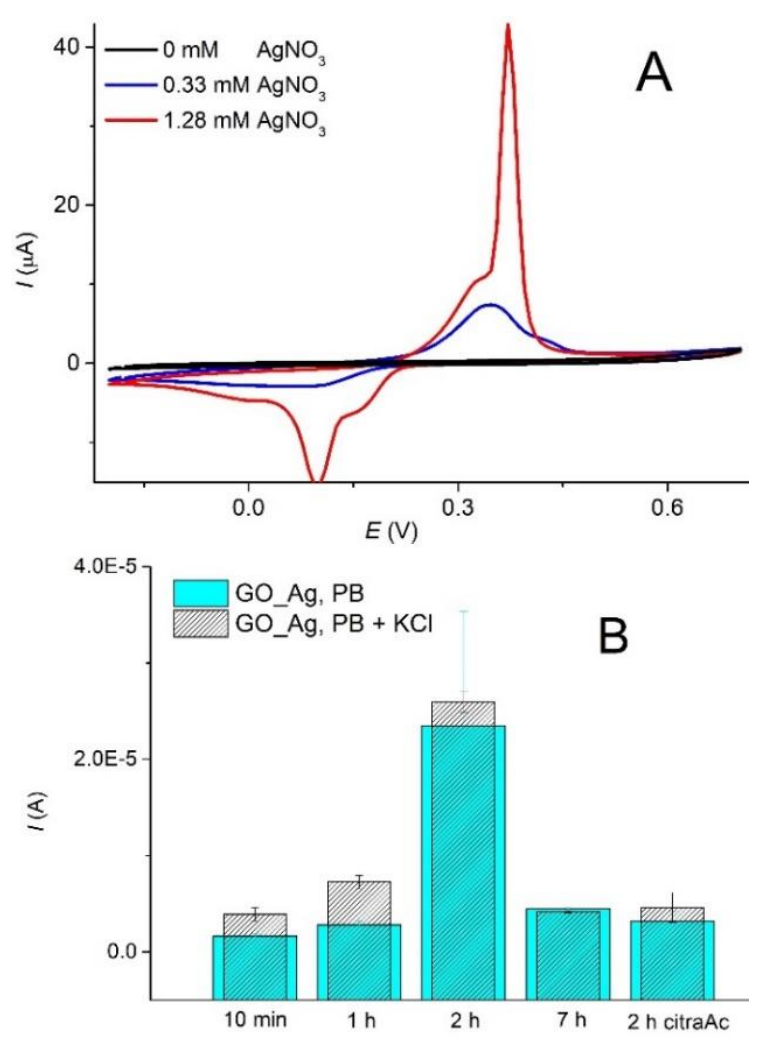

Figure 3: A) CVs of GCEs modified with GO_Ag_C prepared with initial concentration $O$ (black), 0.33 (blue) and 1.28 (black) $\mathrm{mM}$ $\mathrm{AgNO}_{3}$. Measured in $\mathrm{PB}$, scan rate $100 \mathrm{mV} . \mathrm{s}^{-1}$; B) Peak heights of GCEs modified by GO-Ag prepared using different incubation times (indicated in the graph) with and without citric acid (also indicated in the graph). CVs were recorded in presence of 4.75 $\mathrm{mM} \mathrm{KCl}$ (stripped black pattern) and in pristine PB (cyan). In all cases $3^{\text {rd }} \mathrm{CV}$ scans are shown.

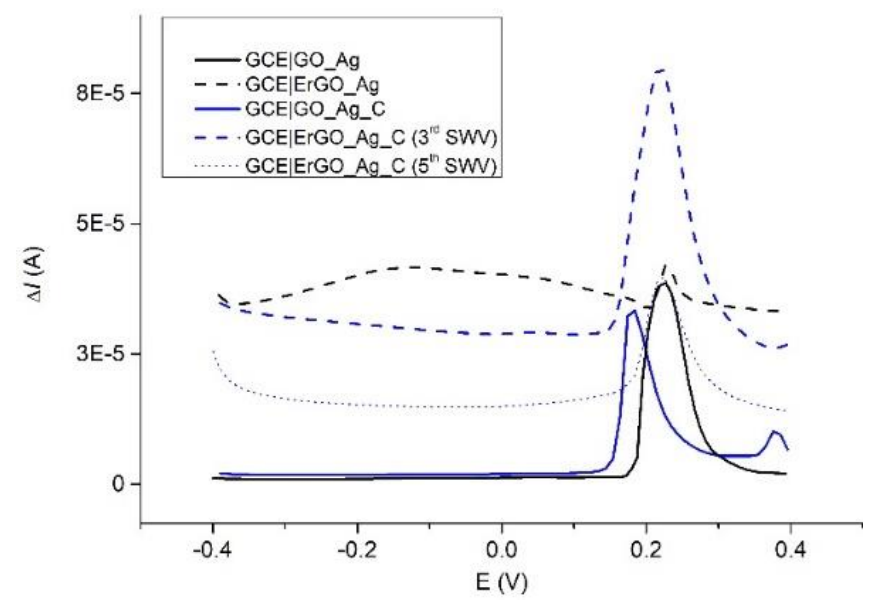

Figure 4: Illustrative SWV voltammograms of electrodes modified with GO_Ag (black solid), ErGO_Ag (black dashed), GO_Ag_C (blue solid) and ErGO_Ag_C ( $3^{\text {rd }}$ SWV - blue dotted and $5^{\text {th }}$ SWV - blue dashed). Measured in $P B$ containing $5 \mathrm{mM} \mathrm{KCl}$, with parameters: deposition time $30 \mathrm{~s}$ and potential $-0.6 \mathrm{~V}$, frequency $25 \mathrm{~Hz}$ and 10 $m V$ modulation amplitude. 
It was observed that ErGO_Ag_C provided a peak height of tens of $\mu \mathrm{A}$ but, without the reduction, only $26 \pm 6 \mu \mathrm{A}$ was measured. These values looks quite satisfying, but the measurements suffered from low stability - when several consecutive SWV measurements were performed, a significant peak height decrease was observed (figure 4). The situation is quite reversed when GO_Ag was employed; after reduction (i.e. GCE $\mid$ ErGO_Ag) only $4 \pm 1$ and $5 \pm 2 \mu \mathrm{A}$ were recorded at first and fifth SWV measurement, respectively (figure 4), but without the reduction (GCE|GO_Ag) quite stable response of $37 \pm 8 \mu \mathrm{A}$ could be observed. The cause of higher response without the electrochemical reduction points out to the fact, that the $\mathrm{AgCl}$ formation and/or oxidation is most probably surface-confined in a way that it is not hindered by GO's low conductivity. On the contrary, GO in this case seems to decrease capacitance current, hence the $\mathrm{AgCl}$ oxidation peak can be more visible. In another words the reduction-driven capacitance makes the discussed peak "buried" and less visible. It should be also noted here that significant increase in surface conductivity after the electrochemical reduction was observed with the use of electrochemical impedance spectroscopy (figure S5).

\subsection{Determination of chlorides}

Next step was to apply the prepared GO_Ag nanohybrids in chloride sensing. It was performed by SWV measurements in PB containing $0.25-10 \mathrm{mM} \mathrm{Cl}$. When $\mathrm{GO}_{-} \mathrm{Ag}$ was investigated (figure 5), the calibration line slope of $8.52 \pm 1.46$ $\left(\mu \mathrm{A} \cdot \mathrm{mM}^{-1}\right)$ and the intercept of $1.59 \pm 0.23$ was observed, but only in a concentration range of $0.25-2.5 \mathrm{mM}$. Better results were obtained when nonlinear fitting was applied. Namely, $2^{\text {nd }}$ order polynomial function in the concentration range $0.25-$ $10 \mathrm{mM}$ (figure 5) returned an equation of $I(\mu \mathrm{A})=-1.04 \pm 0.84$ $+11.6 \pm 3.3 \times c(\mathrm{mM})-0.73 \pm 0.32 \times c^{2}$. It was also observed that the peak potential depends on the chloride concentration, in agreement with other studies [37, 44]. The potential shift is based on Nernst's equation and, given by the net reaction $\mathrm{Ag}^{0}$ $+\mathrm{Cl}^{-} \rightarrow \mathrm{AgCl}(\mathrm{s})+\mathrm{e}^{-}$, it can be inferred that the reaction potential will be dependent on logarithm of $\mathrm{Cl}^{-}$concentration [37]. That was experimentally demonstrated and calibration curves were constructed as semilogarithmic plots of $\log \mathrm{c}$ $(\mathrm{mM})$ versus the peak potential. By this approach the calibration equation $E(\mathrm{~V})=-0.059 \pm 0.004 \times \log c+$ $0.263 \pm 0.002$ was obtained for a concentration range of $0.1-$ $10 \mathrm{mM} \mathrm{Cl}^{-}$(figure 5) with a lower data scattering compared to the calibration method employing the peak height.

A significant difference was observed when the employed electrodes were reduced before the measurement. From figure 5 it is obvious that such electrodes exhibited much lower sensitivity towards $\mathrm{Cl}^{-}$. Two linear regions were observed, that is, from 0.25 to $1 \mathrm{mM}$ and from 2.5 to $10 \mathrm{mM}$, with linear regression equations of $I(\mu \mathrm{A})=-0.151 \pm 0.037+2.99 \pm 0.04 \mathrm{x}$ $c(\mathrm{mM})$ and $I(\mu \mathrm{A})=3.22 \pm 0.18+0.86 \pm 0.04 \times c(\mathrm{mM})$,
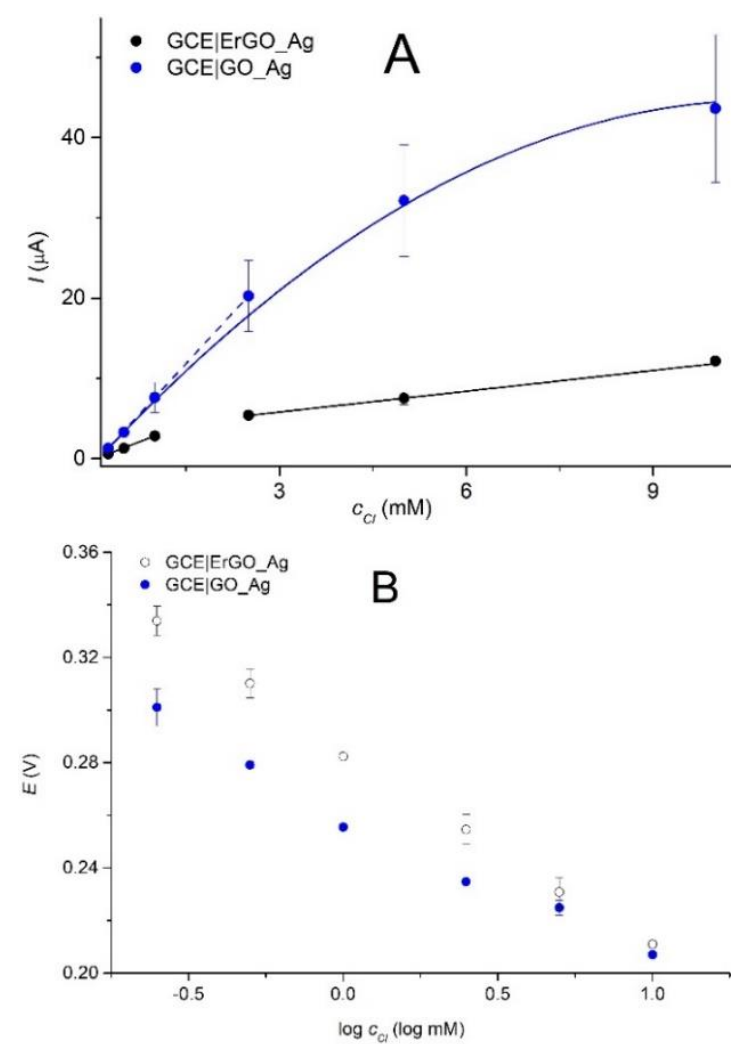

Figure 5: Calibration curves of GCE/GO_Ag (blue) and GCE/ErGO_Ag (black) obtained from peak heights (A) and peak positions $(B)$ read from SWVs in $100 \mathrm{mM} \mathrm{PB,} \mathrm{pH} 7$ containing the required concentration of $\mathrm{KCl}$.

respectively. Interestingly, when the peak potential was used for calibration evaluation, the results were even better. Linear regression with equation of $E(\mathrm{~V})=-0.077 \pm 0.002 \times \log c+$ $0.286 \pm 0.004$ was obtained.

For the obtained calibration curves limits of detection were also calculated using 3-fold standard deviation of the response achieved at zero concentration as the base for the calculation. Achieved values of LOD are given in the table 1 where they are compared with other silver nanoparticle-based electrochemical chloride sensors published elsewhere. It can be concluded that the reached limit of detection and the detection range were not better than most of the published, but they can quite match in terms of LOD.

To explore possible real sensing applications of the fabricated $\mathrm{GO}-\mathrm{Ag}$ nanomaterial, a voltammetric response towards $\mathrm{FeCl}_{3}$ (a common coagulation agent employed in water treatment [63]) was investigated in a tap water amended with a supporting electrolyte $\left(0.1 \mathrm{M} \mathrm{PB}\right.$ or $\left.0.1 \mathrm{M} \mathrm{Na}_{2} \mathrm{SO}_{4}\right)$ and SWV measurements were performed with addition of $0,1,2$ and $3 \mathrm{mM} \mathrm{FeCl}_{3}$ (see figure S6). As expected, $\mathrm{AgCl}$ oxidation peaks appeared at about $200 \mathrm{mV}$ in all cases. Both their height and area were in a linear correlation with the $\mathrm{FeCl}_{3}$ concentration. When sodium sulphate was used as the supporting electrolyte the linear functions $I(\mathrm{~A})=1.04 \times 10^{-6} \mathrm{X}$ 
$c(\mathrm{mM})+1.88 \times 10^{-5}$ and $A$ (A.s) $=5.88 \times 10^{-7} \times c(\mathrm{mM})+$ $1.46 \times 10^{-6}$ were observed for peak height $(I)$ and peak area $(A)$, respectively. On the other side when phosphate buffer was used equations of $I(\mathrm{~A})=7.50 \times 10^{-6} \times c(\mathrm{mM})+1.69 \times 10^{-5}$ and $A$ (A.s) $=6.51 \times 10^{-7} \times c(\mathrm{mM})+3.61 \times 10^{-7}$ were observed for peak height and peak area, respectively. From substantially higher sensitivity in the latter case, i.e. $7.50 \times 10^{-6}$ compared to $1.04 \times 10^{-6}$ it can be concluded that the phosphate buffer environment increased the operational properties of the GO_Ag sensor in tap water samples. These results were obtained despite coagulation of phosphate in presence of $\mathrm{Fe}^{3+}$ which could be observed by naked eye.

\subsection{Influence of $\mathrm{pH}$ and other halide ions}

Interfering reactions of other halides and other ions were also investigated employing SWV in $\mathrm{PB}$ containing $\mathrm{Cl}^{-}$(1 $\mathrm{mM}$ ) and other ion(s) including $\mathrm{I}^{-}, \mathrm{Br}^{-}, \mathrm{F}^{-}, \mathrm{Cu}^{2+}, \mathrm{CO}_{3}{ }^{2-}, \mathrm{NH}_{4}^{+}$ and $\mathrm{CN}^{-}$. It was found that the presence of ammonia and fluoride ions ( $2 \mathrm{mM}$ of ammonium fluoride) as well as of copper and carbonite $\left(2 \mathrm{mM} \mathrm{CuCO}_{3}\right)$ and iodide $(2 \mathrm{mM} \mathrm{KI})$ has not had a significant influence on the chloride ion detection, as can be seen from illustrative voltammograms in figure S7 A (note that peak heights were obtained using "exponential baseline" option in NOVA 2.1 software). On the contrary, slight chloride peak height increase was observed in presence of $\mathrm{CuCO}_{3}, \mathrm{KI}$ and $\mathrm{NH}_{4} \mathrm{~F}$ (peak heights are $116 \pm 29$ $\%, 103 \pm 35 \%$ and $118 \pm 15 \%$, respectively, relative to the signal measured in presence of only $1 \mathrm{mM} \mathrm{KCl}$ ). It can be probably ascribed to a higher ionic strength and conductivity of solutions with added ions. Some interferences were observed in case of $\mathrm{Br}^{-}$presence where the chloride peak height reached only $65 \pm 31 \%$ of the initial response without interfering ions. The largest interferences were observed with $\mathrm{CN}^{-}$ions, which agrees with the fact that $\mathrm{CN}^{-}$also forms complex with $\mathrm{Ag}[36,64]$. On the other side, presumable $\mathrm{AgCl}$ oxidation peak is still observed, from which it can be concluded that the formation of $\mathrm{AgCl}$ occurs even in the presence of $\mathrm{Br}^{-}$and $\mathrm{CN}^{-}$, but these ions compete for the $\mathrm{Ag}$ nanoparticle surface. Also, overlapping of the voltammetric peaks makes precise evaluation quite difficult.

Table 1: Selected operational properties of diverse electrochemical chloride sensors employing silver nanoparticles

\begin{tabular}{lllll}
\hline $\begin{array}{l}\text { Electrode } \\
\text { modification }^{[a]}\end{array}$ & Method & Linear range & $\begin{array}{l}\text { LOD } \\
(\mu \mathrm{M})\end{array}$ & ref. \\
\hline$Q G @ M A-A g N W$ & conductivity & $\begin{array}{l}0.25 \mu M-250 \\
m M\end{array}$ & 0.16 & {$[44]$} \\
\hline$A g N P$ in $C P$ & $D P V$ & $0.005-0.5 \mathrm{mM}$ & 0.5 & {$[45]$} \\
\hline Ag ink-printed $P E$ & $C V$ & $u p$ to $200 \mathrm{mM}$ & 1000 & {$[46]$} \\
\hline AgNP on $S P E$ & $C V$ & $2-40 \mathrm{mM}$ & $N A$ & {$[42]$} \\
\hline$R G O-D N A-A g N P$ & $D P V$ & $1 \mu M-1 \mathrm{mM}$ & 0.2 & {$[39]$} \\
\hline
\end{tabular}

\begin{tabular}{|c|c|c|c|c|}
\hline$G R-A g N P$ & $C V$ & $0.5-50 \mathrm{mM}$ & 61 & {$[40]$} \\
\hline$P t E-A g N W$ & $C V$ & $0.2-20.2 \mathrm{mM}$ & 20 & [36] \\
\hline$A g$ ink-printed $S P E$ & $C V$ & $0.1-20 \mathrm{mM}$ & 18.8 & {$[43]$} \\
\hline AgNP on Gore-Tex ${ }^{\circledR}$ & $C V$ & $3-100 \mu M$ & 2.25 & [41] \\
\hline $\begin{array}{l}\text { AgNP@SWNT/AuNL/M } \\
B-D N A\end{array}$ & $D P V$ & $1-300 \mathrm{mM}$ & $N A$ & [37] \\
\hline \multirow[t]{3}{*}{$G O-A g N P$} & $S W V^{a}$ & $0.25-2.5 \mathrm{mM}$ & 81 & \multirow[t]{6}{*}{$\begin{array}{l}\text { this } \\
\text { work }\end{array}$} \\
\hline & $S W V^{b}$ & $0.25-10 \mathrm{mM}$ & 220 & \\
\hline & $S W V_{-} E$ & $0.1-10 \mathrm{mM}$ & 79 & \\
\hline \multirow[t]{3}{*}{ ErGO-AgNP } & $S W V^{a}$ & $0.25-1 \mathrm{mM}$ & 37 & \\
\hline & $S W V^{a}$ & $2.5-10 \mathrm{mM}$ & 630 & \\
\hline & $S W V_{-} E$ & $2.5-10 \mathrm{mM}$ & 174 & \\
\hline
\end{tabular}

${ }^{[a]}$ Height of SWV peaks, linear fitting. ${ }^{[b]}$ Height of SWV peaks, nonlinear fitting.

QG - hollow Q-graphene; MA - melamine; AgNW - silver nanowires; $\mathrm{AgNP}$ - silver nanoparticles; $\mathrm{CP}$ - carbon paste electrode; PE - paper electrode; SPE - screen printed electrode; RGO - reduced graphene oxide; GR - graphene; PtE - platinum electrode; SWNT single wall carbon nanotubes; AuNL - gold nanoleaves; MB methylene blue; SWV_E - potential of SWV peaks, linear fitting.

In the next step influence of $\mathrm{pH}$ was investigated on GCEs modified by GO_Ag using SWV performed in PB buffers of $\mathrm{pH}$ of 4,6 and 8 in presence of $1 \mathrm{mM} \mathrm{KCl}$. Interestingly, it was found that the $\mathrm{AgCl}$ oxidation peak potential was more or less identical in $\mathrm{pH} 4$ and $6(261 \pm 6$ and $267 \pm 12 \mathrm{mV}$, respectively). On the other hand the peak height was higher at lower $\mathrm{pH}(8.68 \pm 0.12 \mu \mathrm{A}$ at $\mathrm{pH} 4$ and $4.85 \pm 0.84 \mu \mathrm{A}$ at $\mathrm{pH} 6)$. When $\mathrm{pH}$ was increased to 8 the peak pattern has obviously changed. It shifted to higher potentials and split into two peaks while the peak height kept increasing which can be attributed to presumable coordinating activity of $\mathrm{OH}^{-}$ions towards the silver. Illustrative SWV voltammograms can be seen in figure S7 B. From the obtained results it can be said that there is not equivalent number of protons and electrons exchanged during $\mathrm{AgCl}$ oxidation.

\subsection{Response to metazachlor}

To broaden the possible applications of the synthesized GO_Ag, it was also tested as an electrocatalyst for cathodic reduction of chloroacetanilide pesticide metazachlor. It was previously reported that silver may enhance reductive dechlorination of such molecules $[65,66]$ which was used mainly for degradation purposes, but sensing would be also possible [67]. The assessment was performed using CV in potential range $-1.5 \rightarrow 0 \mathrm{~V}$. To avoid signal changes caused by GO_Ag reduction, the GCE|GO_Ag electrodes were first pre-treated by voltammetric cycling in negative potential. It was observed that after 25 scans the voltammetric signal was stable. The consequent measurements were also CVs, performed in $20 \mathrm{mM} \mathrm{NaOH}$ in absence or presence of 100 
mg.L. ${ }^{-1}$ metazachlor (Chemos, Czech republic). In figure 6 it can be seen that there is a cathodic feature, appearing in the metazachlor presence. It is not accompanied by its anodic counterpart which indicates that the observed process is irreversible, just like the electrochemical dechlorination. It should be also noted that this response was not observed in a case when GCE|ErGO electrode was used, neither when $\mathrm{Cl}$ free metezachlor metabolite (metazachlor OA, SigmaAldrich) was investigated (data not shown). It can be concluded that, after appropriate reduction, the prepared GO_Ag nanomaterial can be also used for development of electrochemical sensors for some pesticides.

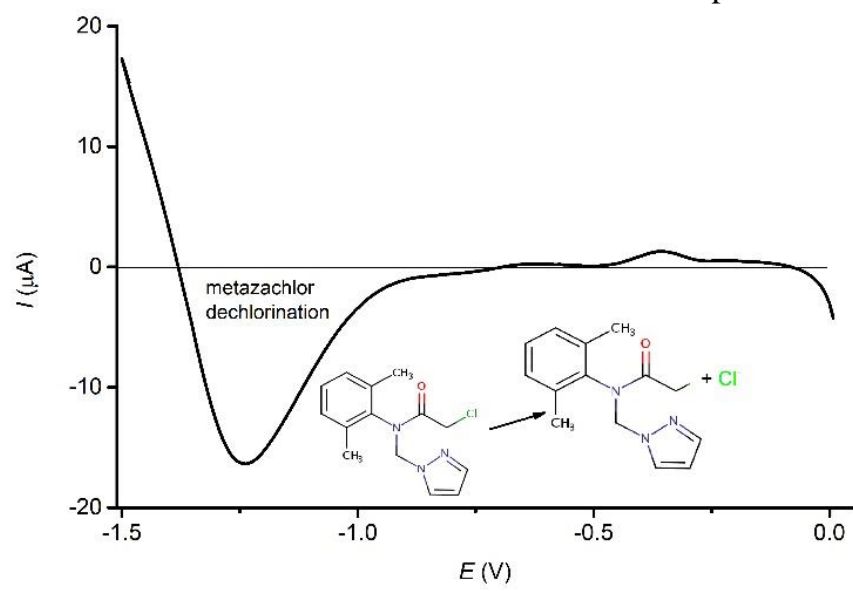

Figure 6: Cathodic part of a background-corrected CV obtained with GCE/ErGO_Ag in $20 \mathrm{mM} \mathrm{NaOH}$ containing $100 \mathrm{mg} \cdot \mathrm{L}^{-1}$ metazachlor ( $3^{\text {rd }} \mathrm{CV}$ scan, scan rate $50 \mathrm{mV} . \mathrm{s}^{-1}$ ). Inside the graph there is illustrated the proposed scheme of metazachlor dechlorination.

\section{Conclusion}

In this work spontaneous deposition of silver on graphene oxide nanosheets from $\mathrm{AgNO}_{3}$ solutions was performed without any additional reducing or alkalization agent or increased temperature, contrary to "conventional" graphene oxide-AgNP synthesis methods. The prepared GO_Ag nanohybrids were first characterized using microscopic and spectroscopic methods confirming the presence of AgNPs attached to the graphene oxide sheets which, importantly, retained its non-reduced state during the synthesis and consequent drying. Next, electrochemical characterization was performed which revealed anodic and cathodic peaks attributed to redox transformation of silver/silver oxides. Also a redox pattern typical for oxidation of $\mathrm{AgCl}$ complex was observed and this peak was used for determination of chloride concentration, employing both the peak height and peak position evaluation. The latter method exhibited linearity over $0.1-10 \mathrm{mM}$ concentration range and a detection limit of 79 $\mu \mathrm{M} \mathrm{Cl}^{-}$, which was better compared to evaluation of peak height and when GO_Ag was reduced electrochemically.

Finally, voltammetric response to $\mathrm{FeCl}_{3}$ in a tap water was investigated with satisfying results and an electrochemical response to chloroacetanilide pesticide metazachlor was also observed.

The spontaneous deposition of $\mathrm{Ag}$ on graphene oxide, as described here, is extremely facile and fast method to obtain GO_Ag nanohybride with good electrocatalytical properties. Not only it can be synthesized with minimum expenses, also their electrochemical versatility is very interesting, especially given a low amount of silver integrated in GO_Ag. Hence applications described in this work may be moved further to, for example, development of environmental or biochemical sensors.

\section{Acknowledgements}

This study was supported by Grant Agency of Czech Republic by a project GACR 20-27735Y. The authors acknowledge TEM measurements performed by Dr. Michal Urbanek and Dr. Ivo Kuritka from Polymer center of Faculty of Technology, Tomas Bata University. Authors also acknowledge XRD experiments performed by prof. Roman Cermak, PhD (Faculty of Technology, Tomas Bata University). The authors also acknowledge Dr. Matej Micusik (Polymer Institute, Slovak Academy of Sciences) for XPS analyses.

\section{References}

[1] Daniel M-C, Astruc D 2004 Gold nanoparticles: assembly, supramolecular chemistry, quantum-size-related properties, and applications toward biology, catalysis, and nanotechnology. Chemical reviews 104293

[2] Astruc D, Lu F, Aranzaes JR 2005 Nanoparticles as Recyclable Catalysts: The Frontier between Homogeneous and Heterogeneous Catalysis. Angewandte Chemie International Edition $\mathbf{4 4} 7852$

[3] Hajipour MJ, Fromm KM, Akbar Ashkarran A, Jimenez de Aberasturi D, Larramendi IRd, Rojo T, et al. 2012 Antibacterial properties of nanoparticles. Trends in Biotechnology 30499

[4] Ouadil B, Amadine O, Essamlali Y, Cherkaoui O, Zahouily M 2019 A new route for the preparation of hydrophobic and antibacterial textiles fabrics using Ag-loaded graphene nanocomposite. Colloids and Surfaces A: Physicochemical and Engineering Aspects 579123713

[5] Ilyas H, Shawuti S, Siddiq M, Niazi JH, Qureshi A 2019 PEG functionalized graphene oxide-silver nano-additive for enhanced hydrophilicity, permeability and fouling resistance properties of PVDF-co-HFP membranes. Colloids and Surfaces A: Physicochemical and Engineering Aspects 579123646

[6] Li N, Chen W, Shen J, Chen S, Liu X 2019 Synthesis of graphene quantum dots stabilized bimetallic $\mathrm{AgRh}$ nanoparticles and their applications. Inorganica Chimica Acta 496119031

[7] Nasrollahzadeh M, Mahmoudi-Gom Yek S, Motahharifar N, Ghafori Gorab M 2019 Recent Developments in the PlantMediated Green Synthesis of Ag-Based Nanoparticles for 
Environmental and Catalytic Applications. The Chemical Record 192436

[8] Dong W, Zhang L, Li B, Wang L, Wang G, Li X, et al. 2016 Preparation of hollow multiple-Ag-nanoclustes-C-shell nanostructures and their catalytic properties. Applied Catalysis B: Environmental 18013

[9] Song X, Shi X 2019 Biosynthesis of Ag/reduced graphene oxide nanocomposites using Shewanella oneidensis MR-1 and their antibacterial and catalytic applications. Applied Surface Science 49168

[10] Wang Y, Zhang M, Yu H, Zuo Y, Gao J, He G, et al. 2019 Facile fabrication of Ag/graphene oxide/TiO2 nanorod array as a powerful substrate for photocatalytic degradation and surface-enhanced Raman scattering detection. Applied Catalysis B: Environmental 252174

[11] Zhou Q, Wang M, Tong Y, Wang H, Zhou X, Sheng X, et al. 2019 Improved photoelectrocatalytic degradation of tetrabromobisphenol A with silver and reduced graphene oxidemodified $\mathrm{TiO}_{2}$ nanotube arrays under simulated sunlight. Ecotoxicology and Environmental Safety 182109472

[12] Turkevich J, Stevenson PC, Hillier J 1951 A study of the nucleation and growth processes in the synthesis of colloidal gold. Discussions of the Faraday Society 1155

[13] Bansal SA, Kumar V, Karimi J, Singh AP, Kumar S 2020 Role of gold nanoparticles in advanced biomedical applications. Nanoscale Advances Advance Article, DOI: 10.1039/D0NA00472C

[14] Evanoff DD, Chumanov G 2005 Synthesis and Optical Properties of Silver Nanoparticles and Arrays. ChemPhysChem, 61221

[15] Dreyer DR, Park S, Bielawski CW, Ruoff RS 2010 The chemistry of graphene oxide. Chemical Society Reviews 39228

[16] Zhang R, Han Q, Li Y, Cai Y, Zhu X, Zhang T, et al. 2019 High antibacterial performance of electrospinning silk fibroin/gelatin film modified with graphene oxide-sliver nanoparticles. Journal of Applied Polymer Science 13647904

[17] Tang J, Chen Q, Xu L, Zhang S, Feng L, Cheng L, et al. 2013 Graphene Oxide-Silver Nanocomposite As a Highly Effective Antibacterial Agent with Species-Specific Mechanisms. ACS Applied Materials \& Interfaces 53867

[18] Choi HC, Shim M, Bangsaruntip S, Dai H 2002 Spontaneous Reduction of Metal Ions on the Sidewalls of Carbon Nanotubes. Journal of the American Chemical Society 1249058

[19] Chen X, Wu G, Chen J, Chen X, Xie Z, Wang X 2011 Synthesis of "Clean" and Well-Dispersive Pd Nanoparticles with Excellent Electrocatalytic Property on Graphene Oxide. Journal of the American Chemical Society 1333693

[20] Spilarewicz-Stanek K, Kisielewska A, Ginter J, Bałuszyńska K, Piwoński I 2016 Elucidation of the function of oxygen moieties on graphene oxide and reduced graphene oxide in the nucleation and growth of silver nanoparticles. RSC Advances 660056

[21] He YQ, Zhang NN, Liu Y, Gao JP, Yi MC, Gong QJ, et al. 2012 Facile synthesis and excellent catalytic activity of gold nanoparticles on graphene oxide. Chinese Chemical Letters $\mathbf{2 3}$ 41

[22] Wang C, Ciganda R, Yate L, Tuninetti J, Shalabaeva V, Salmon L, et al. 2017 Redox synthesis and high catalytic efficiency of transition-metal nanoparticle-graphene oxide nanocomposites. Journal of Materials Chemistry A 521947

[23] Chen H, Li Y, Zhang F, Zhang G, Fan X 2011 Graphene supported Au-Pd bimetallic nanoparticles with core-shell structures and superior peroxidase-like activities. Journal of Materials Chemistry 2117658

[24] Tian T, Zhong Y, Deng C, Wang H, He Y, Ge Y, et al. 2017 Brightly near-infrared to blue emission tunable silvercarbon dot nanohybrid for sensing of ascorbic acid and construction of logic gate. Talanta 162135

[25] He Y, Zhang N, Gong Q, Li Z, Gao J, Qiu H 2012 Metal nanoparticles supported graphene oxide 3D porous monoliths and their excellent catalytic activity. Materials Chemistry and Physics 134585

[26] Wu T, Zhang L, Gao J, Liu Y, Gao C, Yan J 2013 Fabrication of graphene oxide decorated with $\mathrm{Au}-\mathrm{Ag}$ alloy nanoparticles and its superior catalytic performance for the reduction of 4-nitrophenol. Journal of Materials Chemistry A 1 7384

[27] Wu T, Ma J, Wang X, Liu Y, Xu H, Gao J, et al. 2013 Graphene oxide supported $\mathrm{Au}-\mathrm{Ag}$ alloy nanoparticles with different shapes and their high catalytic activities. Nanotechnology 24125301

[28] Kaur B, Pandiyan T, Satpati B, Srivastava R 2013 Simultaneous and sensitive determination of ascorbic acid, dopamine, uric acid, and tryptophan with silver nanoparticlesdecorated reduced graphene oxide modified electrode. Colloids and Surfaces B: Biointerfaces 11197

[29] Chen M, Zhang Z, Li L, Liu Y, Wang W, Gao J 2014 Fast synthesis of Ag-Pd@ reduced graphene oxide bimetallic nanoparticles and their applications as carbon-carbon coupling catalysts. RSC Advances 430914

[30] Bhat SA, Rather MA, Pandit SA, Ingole PP, Bhat MA 2015 Oxides in silver-graphene nanocomposites: electrochemical signatures and electrocatalytic implications. Analyst 1405601

[31] Zhang L, Wang H, Li X, Xia F, Liu Y, Xu X, et al. 2015 One-step synthesis of palladium-gold-silver ternary nanoparticles supported on reduced graphene oxide for the electrooxidation of methanol and ethanol. Electrochimica Acta 17242

[32] Pasricha R, Gupta S, Srivastava AK 2009 A Facile and Novel Synthesis of Ag-Graphene-Based Nanocomposites. Small 52253

[33] Selvakannan PR, Swami A, Srisathiyanarayanan D, Shirude PS, Pasricha R, Mandale AB, Sastry M 2004 Synthesis of Aqueous Au Core-Ag Shell Nanoparticles Using Tyrosine as a pH-Dependent Reducing Agent and Assembling PhaseTransferred Silver Nanoparticles at the Air-Water Interface. Langmuir 207825

[34] Vijay Kumar S, Huang NM, Lim HN, Marlinda AR, Harrison I, Chia CH 2013 One-step size-controlled synthesis of functional graphene oxide/silver nanocomposites at room temperature. Chemical Engineering Journal 219217

[35] Orth ES, Ferreira JGL, Fonsaca JES, Blaskievicz SF, Domingues SH, Dasgupta A, Terrones M, Zarbin AJG 2016 pKa determination of graphene-like materials: Validating chemical functionalization. Journal of Colloid and Interface Science $\mathbf{4 6 7} 239$ 
[36] Qin X, Wang H, Miao Z, Wang X, Fang Y, Chen Q, et al. 2011 Synthesis of silver nanowires and their applications in the electrochemical detection of halide. Talanta 84673

[37] Dong H, Zhang L, Liu W, Tian Y 2017 Label-Free Electrochemical Biosensor for Monitoring of Chloride Ion in an Animal Model of Alzhemier's Disease. ACS Chemical Neuroscience 8339

[38] Bujes-Garrido J, Arcos-Martínez MJ 2017 Development of a wearable electrochemical sensor for voltammetric determination of chloride ions. Sensors and Actuators B: Chemical 240224

[39] Kong F-Y, Li W-W, Wang J-Y, Wang W 2015 UVassisted photocatalytic synthesis of highly dispersed $\mathrm{Ag}$ nanoparticles supported on DNA decorated graphene for quantitative iodide analysis. Biosensors and Bioelectronics 69 206

[40] Yu M, Liu P, Zhang S, Liu J, An J, Li S 2012 Preparation of graphene-Ag composites and their application for electrochemical detection of chloride. Materials Research Bulletin $\mathbf{4 7} 3206$

[41] Bujes-Garrido J, Izquierdo-Bote D, Heras A, Colina A, Arcos-Martínez MJ 2018 Determination of halides using Ag nanoparticles-modified disposable electrodes. A first approach to a wearable sensor for quantification of chloride ions. Analytica Chimica Acta $\mathbf{1 0 1 2} 42$

[42] Toh HS, Batchelor-McAuley C, Tschulik K, Compton RG 2013 Electrochemical detection of chloride levels in sweat using silver nanoparticles: a basis for the preliminary screening for cystic fibrosis. Analyst 1384292

[43] Chiu M-H, Cheng W-L, Muthuraman G, Hsu C-T, Chung H-H, Zen J-M 2009 A disposable screen-printed silver strip sensor for single drop analysis of halide in biological samples. Biosensors and Bioelectronics 243008

[44] Wan Y, Hua Y, Liu M, Li S, Yin M, Lv X, Wang H 2019 Highly selective electroanalysis for chloride ions by conductance Signal outputs of solid-state $\mathrm{AgCl}$ electrochemistry using silver-melamine nanowires. Sensors and Actuators B: Chemical 300127058

[45] Trnkova L, Adam V, Hubalek J, Babula P, Kizek R 2008 Amperometric Sensor for Detection of Chloride Ions. Sensors 8 doi: 10.3390/s8095619.

[46] Cinti S, Fiore L, Massoud R, Cortese C, Moscone D, Palleschi G, Arduini F 2018 Low-cost and reagent-free paperbased device to detect chloride ions in serum and sweat. Talanta 179186

[47] Hui KS, Hui KN, Dinh DA, Tsang CH, Cho YR, Zhou W, et al. 2014 Green synthesis of dimension-controlled silver nanoparticle-graphene oxide with in situ ultrasonication. Acta Materialia 64326

[48] Martínez-Orozco RD, Rosu HC, Lee S-W RodríguezGonzález V 2013 Understanding the adsorptive and photoactivity properties of Ag-graphene oxide nanocomposites. Journal of Hazardous Materials 26352

[49] Samanta S, Pyne S, Sarkar P, Sahoo GP, Bar H, Bhui DK, et al. 2010 Synthesis of silver nanostructures of varying morphologies through seed mediated growth approach. Journal of Molecular Liquids $\mathbf{1 5 3} 170$

[50] Garg K, Papponen P, Johansson A, Puttaraksa N, Gilbert L 2020 Preparation of graphene nanocomposites from aqueous silver nitrate using graphene oxide's peroxidase-like and carbocatalytic properties. Scientific Reports 105126

[51] Evanoff DD, Chumanov G 2004 Size-Controlled Synthesis of Nanoparticles. 2. Measurement of Extinction, Scattering, and Absorption Cross Sections. The Journal of Physical Chemistry B 10813957

[52] Dat NM, Long PNB, Nhi DCU, Minh NN, Duy LM, Quan LN, et al. 2020 Synthesis of silver/reduced graphene oxide for antibacterial activity and catalytic reduction of organic dyes. Synthetic Metals 260116260.

[53] Narayana MV, Jammalamadaka SN 2016 Tuning Optical Properties of Graphene Oxide under Compressive Strain Using Wet Ball Milling Method. Graphene 58

[54] Guo X, Liu G, Yue S, He J, Wang L 2015 Hydroxyl-rich nanoporous carbon nanosheets synthesized by a one-pot method and their application in the in situ preparation of well-dispersed Ag nanoparticles. RSC Advances 596062

[55] Haniyeh F, Abdollah A, Abolghasem D 2013 Controlled growth of well-Aligned carbon nanotubes, electrochemical modification and electrodeposition of multiple shapes of gold nanostructures. Materials Sciences and Applications 2013 article ID 39633 DOI:10.4236/msa.2013.411083

[56] Wang X, Huang P, Liu H, Li C, Shen G, Cui D 2013 Metal ion-directed solution-phase tailoring: from large-area graphene oxide into nanoscale pieces. Nanoscale Research Letters 8226

[57] Mangalam J, Kumar M, Sharma M, Joshi M 2019 High adsorptivity and visible light assisted photocatalytic activity of silver/reduced graphene oxide (Ag/rGO) nanocomposite for wastewater treatment. Nano-Structures \& Nano-Objects 1758

[58] Pavoski G, Maraschin T, Fim FdC, Balzaretti NM, Galland GB, Moura CS, et al. 2017 Few Layer Reduced Graphene Oxide: Evaluation of the Best Experimental Conditions for Easy Production. Materials Research 2053

[59] Stobinski L, Lesiak B, Malolepszy A, Mazurkiewicz M, Mierzwa B, Zemek J, et al. 2014 Graphene oxide and reduced graphene oxide studied by the XRD, TEM and electron spectroscopy methods. Journal of Electron Spectroscopy and Related Phenomena 195145

[60] Ferraria AM, Carapeto AP, Botelho do Rego AM 2012 Xray photoelectron spectroscopy: Silver salts revisited. Vacuum 861988

[61] Malinský P, Macková A, Mikšová R, Kováčiková H, Cutroneo M, Luxa J, Bouša D, Štrochová B, Sofer Z 2017 Graphene oxide layers modified by light energetic ions. Physical Chemistry Chemical Physics 1910282

[62] Zhang R, Xu S, Zhu Y, Luo J, Liu X, Tang D 2016 Onepot facile preparation of $\mathrm{Ag}$ nanoparticles for chloride ion sensing. Colloid and Polymer Science 2941643

[63] Ippolito JA, Barbarick KA, Elliott HA 2011 Drinking water treatment residuals: a review of recent uses. J Environ Qual 401

[64] Khatha P, Phutthaphongloet T, Timpa P, Ninwong B, Income K, Ratnarathorn N, et al. 2019 Distance-Based Paper Device Combined with Headspace Extraction for Determination of Cyanide. Sensors 192340

[65] Pasciak EM, Sengupta A, Mubarak MS, Raghavachari K, Peters DG 2014 Electrochemical reduction of 2-chloro-N- 
phenylacetamides at carbon and silver cathodes in dimethylformamide. Electrochimica Acta, 127, pp. 159

[66] Verlato E, He W, Amrane A, Barison S, Flonger D,

Fourcade F, Geneste F, Musiani M, Seraglia R 2016 Preparation of Silver-Modified Nickel Foams by Galvanic Displacement and Their Use as Cathodes for the Reductive Dechlorination of Herbicides. ChemElectroChem 32084

[67] Carrai P, Nucci L, Pergola F 1992 Polarographic

Behaviour of Alachlor Application to Analytical Determination. Analytical Letters 25163 